\title{
Orientation and innovation of University Library Service in the era of MOOC
}

\author{
Pinxiao Li, Yan Xu \\ Library of Beihua University, Jilin, Jilin, 132013
}

Keywords: MOOC; university library; information literacy; Service Innovation

Abstract: Massive Open Online Courses is triggering a fundamental change in the traditional educational model of colleges and universities. The library plays a key role in the development of MOOC. In the current reform of higher education in China, it is still of practical significance to RECOMB the contents and development status of MOOC. On the basis of the current foreign university library's service content to MOOC, this paper puts forward the idea of the role and orientation of the University Library and the content of service innovation on the basis of the current foreign university library's service content to the university library, in order to provide new ideas and Enlightenment for the development and reform of the University Library in our country.

\section{Introduction}

First, accelerate the library in the "Internet plus education" in the construction; in July 4, 2015, the State Council issued the "guidance on actively promoting" Internet plus "action". Comments pointed out that positive comparative advantage, China's Internet has been formed to enhance confidence, seize the opportunity, accelerate the development of Internet plus ", to reshape the innovation system, stimulate innovation and vitality, cultivate new industry and innovative public service model, and guide the initiative to adapt to the new normal economic development, the formation of economic development It is of great significance to develop new kinetic energy and upgrade the quality and efficiency of China's economy. A school, a teacher, a classroom, this is traditional education. A special education network, a mobile terminal, millions of students, the school, the teacher let you pick your choice, this is the "Internet plus education", so the University Library in the "Internet plus education" plays an important role.

Effect of Internet plus education not only entrepreneurs, there are some platform can achieve employment opportunities, occupation training online education platform can provide a number of people will be able to achieve the functions of training, will be able to solve the employment and entrepreneurship. The premier's "public entrepreneurship and innovation" has far-reaching implications for education. Education is not just business, it is similar to Geek College for more than a year, with nearly 1000 vocational and technical courses and more than 4000 hours to help about 800000 IT practitioners improve their professional skills.

With the rise of "Internet plus", the government and enterprises need more "Internet plus" talent, so it will bring about the outbreak of "Internet plus" training and occupation training online education. In the field of online education, vocational education has always been a popular 
educational type, occupying larger market share at the same time. "The training content Internet plus" education can be varied, each post specific breakdown of the work. In fact, these online training posts are essentially the posts of Internet companies. Traditional enterprises want to change their business structure and need more professional skills. "Internet plus" occupation training mainly for two groups, one is the employees of traditional enterprise training, two is to want to be engaged in the industry personnel training.

With the rapid development of Internet computer technology, the large-scale online open course, MOOC (Massive Open Online Courses), started a wave in the United States in 2011. The online education platform based on the Internet is not limited by time and place. The emergence of MOOC has achieved a transcendence of the traditional education model of the face-to-face teaching, with the aim of achieving the opening and sharing of the global quality education resources. [1]The advantages of MOOC open platform play a huge potential role in education reform, and it is also a new fulcrum to promote library reform [2]. In 2015, the Ministry of Education issued a document on strengthening the application and management of the construction of online open courses in Colleges and universities, which clearly defined the importance of carrying out large-scale online courses in Colleges and universities and regarded it as one of the future trends of higher education. [3]The library is an indispensable part of higher education. It is the information center of document processing. It is an academic institution for scientific research and teaching. It is in the position of the source of knowledge in Colleges and universities. With the arrival of library 2, the coexistence of digital and physical form of information space will become the future development trend of the library, and is also a perfect supplement to the MOOC.

According to the development of MOOC and the current situation and characteristics of the University Library in China, it is very important to study the new service model of the University Library in accordance with our country, which is very important to the development of the library. Based on the content characteristics of MOOC and the practice of carrying out MOOC service in foreign university libraries, this paper combs and analyzes. Based on the analysis of the role of the University Library in China, the suggestions and lists of the service innovation of the University Library in China are put forward, in order to provide some reference and reference for the promotion of the function reconstruction of the University Library in China.

\section{The origin and characteristics of two and MOOC}

\subsection{The origin and development of MOOC}

In 2007, David Wiley launched the initiative of launching a world open curriculum sharing course through wiki. Although it has not been recognized and attached to people's attention, it has opened the prelude to the MOOC course. Then, in 2008, Stephen Downes and George Simmons of University of Manitoba, Canada, launched the first online online education course to the world. Through the spread of social networking sites, more than 10 thousand users were attracted and shared on the same day. The practice of the course further laid the foundation for the birth of the MOOC course model the foundation [4]. In this regard, Blaine yalex and Dave Mir of the United States first proposed the concept of MOOC, which is defined as a large-scale online course, and the Chinese translation is also called the mousse. In 2012, MOOC came into a new breakthrough. Two professors of Stanford University's Peter and Bastien dragons opened the free online course "Introduction to artificial intelligence", which attracted more than 170 thousand users from more than 190 countries, attracted the attention of the academic community and aroused strong social repercussions. MOOC has formally entered the field of vision. After that, MIT and Harvard University jointly set up the online education platform (edX), and the Stanford University professors set up the online education platform of the "Coursera" and "online university" (Udacity), 
which are called "three carriages" of online education. In 2012, MOOC flourished and was called "the year of Mogao class" by the New York Times. In 2013, Tsinghua University and Peking University announced their cooperation with edX. Among them, Tsinghua University opened the world's first Chinese version of the MOOC curriculum platform - school online. At this point, MOOC has attracted more and more scholars' attention and research at home and abroad. At present, libraries in many foreign universities have taken the lead in providing a substantial service for university teachers and students to participate in MOOC through a variety of services. [5]According to the relevant survey, as of December 2015, a total of 721 University Libraries in China carried out 9.71\%only. [6] Generally speaking, the service consciousness of our university libraries is not strong enough for MOOC, and the service is also lacking in depth.

\subsection{The characteristics of MOOC}

With its own advantages, Mogao has gained popularity in the world rapidly and is being sought after by more and more people. Through analyzing the content of Mogao class, Mogao mainly has the following five characteristics. One is on a large scale. Moore can break the limitation of the number of participants in traditional courses. MOOC has gathered a large number of high-quality educational resources from all over the world, with a large number of participants and wide coverage. The two is openness. Anyone who has interest in learning can register through Mogao net. There are no barriers to entry, such as nationality, age and sex. The three is network. Through network media, we can teach and learn to break the traditional face-to-face instruction. Four is personalization. The learners can choose the course content freely according to their own interests, time and place, and enjoy the high quality courses of the world's top universities anytime and anywhere, and have the characteristics of individualized and humanized. The five is interactivity. Mogao encourages learners to learn and communicate with each other, and is committed to creating a learning atmosphere that is compatible with the socialization of contemporary people.

\section{The impact of three and MOOC on the service of University Library}

\subsection{The relationship between MOOC and University Library}

MOOC as an online education, though apparently, has no significant connection with university libraries. However, in fact, both the way to acquire resources and the content of learning are inseparable from the support of educational resources in university libraries. University library is a platform for information search and acquisition of teachers and students. It has the ability to provide rich and open resources and information literacy. It can be said that in the process of training higher education talents, no other courses can replace the role and status of University Libraries in information literacy, information consultation, teaching services and so on. The relationship between MOOC and libraries should be partners and mutual promotion. The image says that if MOOC education is knowledge processing, the library is the source of knowledge for MOOC students.

\subsection{The challenges facing the service of University Library}

\subsubsection{Lack of information literacy training}

For MOOC learners, on the one hand, they accept new knowledge. On the other hand, it is a test of learners' ability to search and acquire information. This is because the learners have received a large amount of learning information in a short period of time. The diversity of information 
resources, unstructured data and informal communication are very uncertain. It is difficult for learners to collect and process effective information. The ability to absorb and digest MOOC knowledge effectively requires learners to have the ability to search, process and analyze information effectively. Learn to extract valuable information from complex information and make use of it. Higher information literacy is the important foundation to ensure learners' learning effect. The university library plays an important role in cultivating students' information literacy, training students to find problems, dealing with problems and solving problems. At the same time, the library can provide relevant professional knowledge for the learners through various ways. For example, the library of University of North Carolina-Chapel Hill has set up the MOOC course for metadata as a required course to provide information literacy courses for the students to adapt to the ability of learner autonomy and information literacy in the context of the MOOC era. [7]At present, our university libraries have not yet established the mechanism of how to guide and train learners, and there is still no effective system training plan.

\subsubsection{Lack of active service capacity}

The orientation of university libraries for a long time is centered on the learning of service courses, providing information centers and academic service organizations. [8] Although the computerization of information resources has become the development trend of the university library, the service of the library still has no qualitative change for the information demand, mainly for the service of improving the borrowing service, the information retrieval, the download of the digital resources, the recommending guidance and so on. It is the passive response and the lack of the service. Practicality, precision and timeliness. However, in the age of knowledge explosion, both students and teachers want to be able to quickly and easily grasp the information processing tools, increase the channel of knowledge acquisition, improve the learning analysis and knowledge information literacy. Especially with the MOOC online education. Liu Xiaoou points out that, in the MOOC era, the information needs of teachers and students in Colleges and universities will change. The learners who receive MOOC education emphasize the autonomy of learning and need learners to search for the learning resources related to the curriculum independently. It is no longer like the educational mode of the passive learning of passive learning led by the teachers under the traditional teaching mode. [9] In the era of MOOC, learners' search for help from libraries will become an inevitable choice. However, at present, the university library has less knowledge about the content of MOOC teaching and the progress of the class, and the service is lack of effectiveness and pertinence, and the ability of active service is insufficient.

\subsubsection{Weak sense of cooperation}

The development of MOOC can not be separated from the support of the library. Through the establishment of a cooperative relationship with the library, the MOOC can quickly integrate into the higher education, and it is likely to lead to a new round of MOOC change. [10] Foreign university libraries realized the importance of cooperation with MOOC earlier. Relying on big data related technologies, embedding MOOC services content and building digital libraries. The library of Stanford University has established a partnership with SIPX to ensure that every teacher knows about the copyright issues involved in the MOOC curriculum. The library of Duke University is embedded in the MOOC platform, providing one-stop teachers with the technical problems of collecting curriculum resources and providing video recording. In order to save the students' time, the University of Washington library directly links the learning links in the learning management system such as Blackboard, Moodle, Canvas and so on. The students can directly access the information content of the library without the need to leave the MOOC learning platform. 
[11]However, most university libraries in China have not paid enough attention to it, and the exploration of MOOC cooperation is relatively few. Wan Wenjuan pointed out that the current cooperation between university libraries and the MOOC platform in China needs to overcome more difficulties. The services are relatively basic and lack the necessary technical support, and the overall development is still in its infancy. [12]

\section{The role orientation of University Libraries in China in the era of MOCC.}

How to deal with the opportunities and challenges brought by MOOC is of great importance to the development of libraries. R. Lue, director of Harvard X at the Harvard University, points out that in the context of the MOOC era, the library should provide help for teachers to carry out courses, and also provide important reference and guidance for the students to explore the knowledge in depth, and make the mission of the library to the greatest value. Professor Linda C.Smith of the University of Illinois points out that libraries can help the design, production and intellectual property rights of teachers' curricula, while librarians should improve their information help and support to the learners. Therefore, the positioning of the library should not only be the organization of information storage and processing, but should be developed with the times, with the development of MOOC, and bring new changes to higher education in China.

\subsection{Promoters of the MOOC movement}

MOOC is an educational resource, which is the role of providing online educational resources, and the library is also the provider of learning resources in the educational chain. The role of the two is fit to some extent. The original intention of the MOOC design is to allow more people to accept higher education. This is also the elaboration of modern and contemporary library service concept. Because in the development environment of networking, digitalization and semantics, libraries are always the drivers of resources and knowledge flow. On the one hand, the library provides the downloading and reading services of information resources; on the other hand, in order to adapt to the mobile Internet environment, the library is also actively expanding its own services, such as the development of the mobile library and the applause library. Therefore, the library is the best promoter of MOOC.

\subsection{Provider of MOOC resources}

With the concept of open, network and sharing as the concept of MOOC teaching mode, to realize the idea of learning at anytime and anywhere, break the traditional closed mode of education, the resources from closed and static to the sharing and open, get the consistent praise of the users. However, due to openness, the resources used by teachers' teaching have been restricted by them, such as the copyright of textbooks. Therefore, an important role of the library is to help teachers choose teaching resources that can be used in MOOC open courses to avoid copyright problems or disputes. The Duke University library is a university library that has earlier noticed the copyright issue of MOOC courses abroad. In order to avoid the copyright issues involved in the MOOC course, the Duke University library provides the support services for the teachers in copyright, provides the corresponding reference guide for the teachers taught by the MOOC, and answers the problems in time. The library should help teachers complete MOOC teaching and share the role of MOOC resource sharing through the sharing and opening of teaching resources. 


\subsection{Information literacy trainer}

In the wave of MOOC, both students and teachers are faced with the challenge of information literacy, and education is one of the roles that university libraries need to undertake, especially in information literacy education. Information literacy refers to the ability to retrieve, collect, analyze and utilize a variety of information sources to obtain information requirements, and is also one of the ability requirements of autonomous learning. On the one hand, in order to enable students to make full use of MOOC's teaching resources and have the ability to search for relevant documents and materials autonomously. On the other hand, in order to make teachers meet the problems of resource acquisition, resource copyright and charge standards in the course of MOOC teaching, teachers can be solved in time, and teachers are also faced with the test of information literacy. Therefore, libraries should actively carry out information literacy training to help teachers and students better develop MOOC.

\subsection{Supporters of MOOC learning}

University Libraries in the mobile Internet age have changed from single resource service to support user learning and education. The most popular concern of online education is how to effectively support user learning. In the teaching of MOOC, classroom learning can only play the role of guiding, and more in-depth study requires students to study and study outside the classroom. This requires the library to serve as a supporter, provide students with high quality curriculum reference information online access services, and deal with all kinds of students in their study in time. The problem. For example, the American University and the Research Library Association demands that the library do not restrict the region, provide MOOC related services and resources for each student as far as possible, and perform the main functions and missions of the university library.

\section{The service innovation of University Library in the era of MOOC.}

\subsection{The continuous enhancement of the publicity of MOOC}

MOOC's learning emphasizes the concept of autonomous learning, which is the collection, organization and utilization of information and knowledge. As the core of the study, the library should be able to actively promote and guide the learners to learn the MOOC, and help the learners to understand and understand what is MOOC, which is also an important content of the MOOC service in the university library. First of all, libraries should popularize the understanding of MOOC among teachers and students in universities by means of network, lectures and course learning. In order to make the learners better learn the MOOC course, the library should carry out the information literacy training regularly, in order to strengthen the learners' information literacy ability as the fundamental goal, and take the practice assessment method to the participants in the training, in order to help the learners get better results. Secondly, the university library should strengthen the cooperation between the school level MOOC, integrate the specialty courses of different colleges and universities, create the University alliance platform and share the MOOC courses of each school together. Finally, university libraries should expand information resources. Fully excavate the information of MOOC, collect, select, arrange, classify and organize, establish the specialized resource navigation of the specific MOOC, present a variety of resources to the learners, provide a convenient one stop search service, and provide a convenient path for the learners to obtain the relevant learning information of the MOOC. 


\subsection{Active participation in the production of MOOC courses}

The quality of MOOC courses depends not only on the content of the course, but also on the effectiveness of MOOC courses. According to the 2013 survey of the chronicle of higher education in the United States, the average time for each professor to record MOOC courses is more than 100 hours, including the collection of curriculum data, the preparation of video recording, and so on. Many universities abroad have begun to integrate MOOC courses into library collaboration. The current MOOC courses in China are mainly opened by a small number of institutions of higher learning. This is because the development of MOOC is constrained by the financial strength of institutions of higher learning and the policy of running a school. In general, most of the universities in our country have not yet realized the importance and revolutionality of the development of MOOC, but simply treat the MOOC as an ordinary network course. According to the development of MOOC in foreign countries, the excellent MOOC course needs not only the teaching teachers but also the cooperation and cooperation of librarians and technicians in order to complete a high quality MOOC course. In order to make the learners feel better learning effect, the library should actively participate in the production of the MOOC course, combine the advantages of the University, make full use of the library resources, help the teachers to complete the production of the MOOC course. At the same time, we should also ensure the teaching resources of the teachers, provide the copyright service, and make clear the copyright. The problem of belonging.

\subsection{Speeding up the construction of Digital Library}

At present, the support of University Libraries in our country is insufficient for the support of MOOC learning. On the one hand, the traditional university library only provides information collection, search, download and other functions, and can not provide personalized information search, retrieval and reading services related to MOOC courses according to the needs of the users. On the other hand, there is a lack of direct communication between users and libraries. Generally speaking, the information communication between users and libraries is a one-way communication mode of "initiate response", which lacks interactive services. The library should actively cooperate with MOOC, provide diversified services for the learners, expand the interactive function of the MOOC platform, promote the construction of the digital library, and follow the support of the large data technology and cloud platform to track and obtain the data about the users on the MOOC platform. Using visual analysis, clustering analysis and data mining technology, the user information needs are analyzed to provide the users with accurate and personalized resource content, and to further enhance the user resource security ability, thus reducing the cost of user information search. Speeding up the construction of digital libraries, providing interactive services, and learning from users' MOOC courses are a trend of keeping pace with the times.

\section{Conclusion}

In the era of information network, the emergence and development of MOOC subverts the traditional higher education model, and brings new opportunities to the teaching ideas and methods of traditional higher education. Although the development of MOOC is still immature, there are still many unsolved problems, but in a few years, the speed of development of MOOC has far exceeded people's expectations. At present, the open and large-scale online education with MOOC as the main representative, in full swing in the world, will bring new changes to the teaching mode of college education, and also bring great impact and challenge to the development of university library, and the service of the library can keep pace with the times. The book should combine its own service advantages and the status of the development of MOOC, change the service concept, 
actively participate in the development of MOOC, and actively contribute to the development of MOOC, thus promoting the reform of China's higher education.

\section{Acknowledgements}

Notes: This paper is for "2018 Jilin Provincial Department of education "13th Five-Year" Humanities and Social Sciences Planning Project”

\section{References}

[1] Wan Wen Juan. Research on Library MOOC services cooperation from the perspective of stakeholders. [J]. Library and information services, 2015, 59 (21): 45-49.

[2] ye yan. Ming. Mogao leveraged the fulcrum of the library's new changes [J]. National Library Science, 2014 (2): 3-9.

[3] Ministry of education. The opinion of the Ministry of education on strengthening the application and management of the construction of online open courses in Colleges and universities [EB /OL.[2016 -07-26] http: / /www.gov.cn /xinwen /2015 -04 /28/content_2854088.htm.

[4] Gore H.Massive open online courses ( MOOCs) and their impact on academic library services: Exploring the issues and challenges [J]. New Review of Academic Librarianship,2014,20(1) : 5 -28.

[5] Zhang Dan, Gong Xiaolin. The practice and Enlightenment of University Library's participation in MOOC copyright service -- Taking Duke University library as an example [J]. Library and information work, 2014,58 (10): 90-93.

[6] Lijun E, Xuehong Zhang, Qiyun Wang. Current situation and Countermeasures of developing mob service in University Libraries [J]. library and information service, 2015,59 (24): 78-82.]

[7] Kara Kohn. As the Spirit MOOCs You: Massive Open Online Courses and Illinois Libraries [EB/OL] [2016-7-01].http://www.ila.org/Reporter/October_2016/

[8] Pages_4-7.pdf.

[9] Long Gao, Fang Guan, run Nan Yan. Challenges and opportunities of MOOC for university library services [J]. Library and information service, 2016,59 (Supplement 2): 77-79.

[10] Discussion on coping strategies of University Libraries under Xiaoou Liu MOOC environment [J]. Library and information work, 2015(11): 92-98.

[11] AI Rong Chen. Analysis of the functions of University Libraries under the MOOC wave [J]. Library and information work, 2016(26): 20-26.

[12] Jie Yang, Yongcui Yuan. Practice and Enlightenment of MOOC services in American Academic Libraries [J]. Library science research, 2014, (12): 85-89.

[13] Wenjuan Wan. Current situation and strategy analysis of MOOC service in Chinese university libraries, [J]. National Library Journal, 2016 (03): 34-39. 